\title{
The effect of an integrated approach to teaching literature on EFL learners' motivation and attitude
}

\author{
Amirani, Delaram $\triangle$ \\ University of Guilan, Iran (delaram_amirani69@yahoo.com) \\ Tahriri, Abdorreza \\ University of Guilan, Iran (atahriri@gmail.com) \\ Barekat, Behzad \\ University of Guilan, Iran (behzadbarekat@yahoo.com)
}

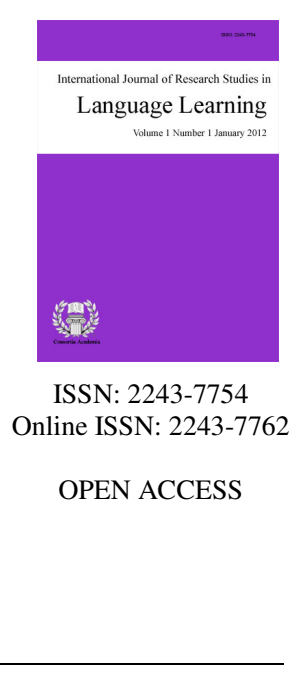

\section{Abstract}

This study reports on an investigation into the motivation and attitudes of Iranian EFL learners towards an integrated approach to teaching literature that was a blend of three models, i.e., language model, cultural model, and personal growth model. To this end, the study was carried out among 40 female EFL learners of intermediate level with 12 hours of instruction in a language center in Rasht, Iran. The participants were randomly assigned into two groups, namely an experimental and a control group. In the experimental group, the suggested integrated approach was utilized whereas the method used for the control group was based on the lecture-based one. A pre-test post-test control group design was followed and the data were collected through attitude and motivation questionnaires. The results revealed that both groups improved in terms of their motivation, of which the magnitude for the experimental group was higher. In addition, the participants in the experimental group held very positive attitudes towards the integrated approach and literature overall and they favored the integrated approach more than that of the control group. The findings shed some light on why and how to teach English literature in EFL classes and provide some recommendations for students, teachers, policy makers, and syllabus designers in order to move from traditional approaches to more innovative ways of teaching literature.

Keywords: integrated approach; teaching literature; motivation; attitude; EFL 


\section{The effect of an integrated approach to teaching literature on EFL learners' motivation and attitude}

\section{Introduction}

There has been an increasing awareness of the significance of integrating literature in EFL/ESL curriculum in recent years. In the era of Grammar Translation Method (GTM), literature was initially the main source of input for teaching in English classes since its main focus was on reading and translating literary texts as good examples of writing and "illustrations of grammatical rules" (Duff \& Maley, 1990, p. 3; cited in Rahimi, 2014). However, as the Communicative Language Teaching (CLT) emerged in the late 1970s, literature was neglected and more attention was given to dialogues and conversations which were more practical and visible in the real world situation (Khatib, Rezaei, \& Derakhshan, 2011). After being neglected for a long time, literature was revived as a language learning material in the middle of 1980s (Duff \& Maley, 1991).

The interrelatedness of language and literature cannot be denied since they are closely interwoven. Literature is language and language can indeed be literary. In other words, literature is said to be fundamentally a study of the language, and literature is language in use and cannot be separated from language (Widdowson, 1985). Brumfit and Carter (1986) claimed that there is no such a thing as literary language. Literature is semantic density of language; in other words, the language used in literary texts is the same as the common language in which linguistics features like similes, metaphors, poetics lexis, and unusual syntactic patterns are used (Lazar, 1993). Thus, literature is not a language variety and language study and literature study are integrated and harmonized (Brumfit \& Carter, 1986).

In addition, motivation is one of the most important factors in learning a second or foreign language. Authenticity and meaningful contexts are the features that make literary texts highly motivating (Ghosn, 2002). The focus of the present study was to use an integrated approach to teaching literature and literary texts in order to explore its effectiveness on EFL learners' motivation and attitudes. In his book, 'literature and language teaching', Lazar (1993) stated that literary texts motivate language learners due to their content and diversity of activities which entail human dilemmas and conflicts that might arouse learners' emotional reflections. The primary purpose is to help teachers and students to move from traditional approaches to more innovative ways in teaching/learning literature as increasing their motivation, and in the second place to make the policy makers, syllabus designers, and material producers aware of the significance of incorporating literature in EFL classes.

\subsection{Statement of the problem}

Little has been done on teaching literature in Iranian EFL context and as Bernhardt (2001) stated, "few empirical contributions on foreign language literature teaching exist" (p. 2; cited in Divsar \& Tahriri, 2009). From the mid-1980s, literature has become a popular teaching resource. The publications of different textbooks on the role of literature in language classes shed light on this issue (e.g., Duff \& Maley, 1991; Gower \& Pearson, 1986; Hill, 1986; Lazar, 1993; Maley \& Duff, 1989; McRae, 1991); however, there is still controversy over the use of literature for the aim of language teaching and learning. Literature is ignored by some scholars as a source of language teaching and learning since they just believe in the aesthetic aspect of literature in addition to their students' lack of proficiency and capability in coping with literary texts (Bassnett \& Grundy, 1993). Moreover, some teachers do not integrate literature into their instructions and use it just as a simple language activity (Wasanasomsithi, 1998). On the other hand, some scholars believe that literature expands the linguistic knowledge of the learners (Povey, 1967). Pugh (1989) also argued that literature is a rich source of meaningful input especially in EFL settings.

What motivated this research were the problems observed in EFL literature classes. Sadeghi (2005) believes 
The effect of an integrated approach to teaching literature on EFL learners' motivation and attitude

that lack of motivation among Iranian students is one of the main reasons that has made teaching English a difficult task (cited in Khodashenas, Amouzegar, Farahani, Hasheminasab, \& Kazemian, 2013). According to Duff and Maley (1991), literature, as an authentic text, is one of the most motivating resources for language learning that triggers the interest in integration of literature and language. Nuttall (1996) also argued that "authentic texts can be motivating because they are proof that the language is used for real-life purposes by real people" (p. 172). Besides, exposing the learners to real language is extremely motivating since they extract real information from a real text in a new and different language (Guariento \& Morley, 2001). Thus, the use of literature in EFL classes might be a good means of boosting students' motivation.

\section{Literature review}

There are three main reasons for using literature in EFL classes: linguistic, methodological, and motivational (Duff \& Maley, 1991). Regarding the motivational reason, which is the concern of the present study, literature involves affective, attitudinal, and experiential factors and may motivate learners to read (McKay, 1986). Thus, literature is motivating since topics related to learners' personal experience are addressed in it (Duff \& Maley, 1991).

\subsection{Theoretical background}

There are different approaches to teaching literature in EFL classes (Wellek \& Warren, 1948; Maley, 1989; Carter \& Long, 1991; Lima, 2005; Van, 2009). Among these main existing approaches, Carter and Long's (1991) models were followed in this study as the 'Integrated Approach'. They suggested three main models for the purpose of integration and incorporation of literature into EFL syllabi that was pursued in the present study. In Language Model, literature is considered as a vehicle for language awareness and development. Literary texts are implemented as a rich source of contextualized linguistic features in this model which is not concerned with the quality of literary texts. In Cultural Model, cultural notions like biography of the authors, genres, history, literary theories, etc. are transmitted to the learners (Carter \& Long, 1991). In this model, literary texts are viewed from different perspectives including social, political, historical, and literal ones. Finally, in Personal Growth Model, learners are actively engaged in reading process through sharing their personal experiences. By interacting with literary texts, learners enhance their language awareness and personal development (Carter \& Long, 1991).

Motivation has been widely accepted by both teachers and researchers as one of the key factors that influence the rate and success of second/foreign language learning (Mao, 2011). In other words, motivation is considered as one of the key factors that determines second/foreign language achievement and attainment (Gardner, 1985; Scarcella \& Oxford, 1992; Skehan, 1991; Oxford \& Shearin, 1994; Dörnyei, 1994). It has been defined differently according to different perspectives and due to the existence of different contexts of language learning; thus, it does not have a particular definition. Gardner (1985) defined motivation as "the combination of effort plus desire to achieve the goal of learning the language plus favorable attitudes toward learning the language" (p. 10). In addition, Brown (1994) stated that "motivation is commonly thought of as inner drive, impulse, emotion, or desire that moves one to a particular action" (p. 152). Dörnyei and Ottó (1998) also defined motivation in second language (L2) learning as "dynamically changing cumulative arousal in a person that initiates, directs, coordinates, amplifies, terminates and evaluates the cognitive and motor processes whereby initial wishes and desires are selected, prioritized, operationalized and (successfully or unsuccessfully) acted out" (p. 65). In SLA, it refers to the attempt and desire to learn a language and positive attitudes towards learning it (Dörnyei, 1994). Oxford and Shearin (1994) add that motivation determines the extent of active, personal involvement in second/foreign language learning. Studies indicate that students' motivation has influenced their attitudes and achievement in learning (Berg, 2001; Shih \& Gamon, 2001). 


\subsection{Research background}

In this section, previous studies related to teaching literature and its effect on learners' motivation and attitudes are reviewed briefly:

Akyel and Yalçin (1990) investigated EFL senior high school students' reactions to the contributions of prose fiction, drama, and poetry in developing language and literary competences. Based on the interpretations of the results, it was found that students regarded novel as the most effective literary form in developing language skills and cultural awareness, and drama as the most effective one in improving oral expressions. Moreover, students considered poetry and short stories not having much effect on their language skills. In addition, it was found that the students who had high English proficiency held more positive attitude toward literary texts; on the other hand, those who had less proficiency found literature boring and difficult.

In their survey study, Davis, Kline, and Hsieh (1992) investigated undergraduates' attitude toward the study of literature in a foreign language, as well as factors affecting their opinions about literature in general. Analyses of the participants' responses to a questionnaire revealed that most of them held positive attitudes toward foreign language literature. Further, the amount of leisure reading in foreign language and the preferred learning styles were the two factors affecting participants' attitude toward literature study. It was concluded that students' attitude toward literature may be influenced by their own different experiences and the teachers' instructional methods.

Timucin (2001) tried to investigate and reflect the response of Turkish undergraduates to an integrated approach of literature teaching, comprising language-based approaches and stylistics, in the Turkish EFL context. His study involved an experimental group exposed to the proposed teaching approach, and a control group undergoing the teaching process they were used to having. Qualitative and quantitative investigations of data gathered through interviews, questionnaires and field notes in both groups were compared and contrasted. The findings revealed significant differences in the nature of students' responses to the teaching approaches they received. Moreover, it was observed that there was a significant relationship between the teaching methodologies employed in both classes, and levels of motivation, involvement, and appreciation of literary texts.

Meristo's (2009) narrative research dealt with the motivational aspects of teaching English culture and literature. Based on the constructivist learning principle, the researcher created two courses in order to teach English culture to pupils aging 14-16. The data were gathered through observations, interviews, group discussions, and notebook documentations. The analyses of the qualitative data indicated that authentic materials and constructivist learning methods raise intrinsic motivation.

T-seng (2010) did a study on teachers' presentations and students' perceptions of literature in general during a 14-week experiment. The participants were 28 Taiwanese EFL senior high school students responding to a 50-item questionnaire. The teacher-researcher presented the literary texts using internet resources and supplementary media materials. The results showed that most of the students liked to be introduced to more literary works and they liked novels, followed by plays, short stories, and poetry. In addition, they liked to read contemporary works rather than classic literature.

Yilmaz (2012) investigated the attitudes of 105 undergraduates towards the study of English literature as well as the factors affecting their opinions during thirteen weeks of experiment. In this survey, a 27-item questionnaire was utilized in order to gather the required data. The results revealed that the majority of the students had positive attitudes towards literature. It was concluded that literature would facilitate foreign language learning. Finally, it was suggested that students should be exposed to more literature courses in order to improve language learning.

Vural (2013) carried out a study on literature and authentic literary materials and their relationship to ELT students' motivation for one semester, using two homogeneous groups, namely experimental and control groups. 
The experimental group was exposed to unabridged, authentic short stories whereas control group was exposed to abridged and simplified texts and reading passages. The findings showed that the experimental group's overall results were better than that of the control group. Moreover, the results of an attitude survey used to understand the level of motivation, suggested that use of short stories enhanced learning and may be beneficial to language practitioners in their classroom teaching.

The present study aims at investigating how an integrated approach to teaching literature influences learners' motivation and attitude in an EFL context. Specifically, the study addresses three research questions:

$>\quad$ Does an integrated approach to teaching literature have any significant effect on intermediate EFL learners' motivation?

$>\quad$ Does an integrated approach to teaching literature have any significant effect on intermediate EFL learners' attitudes towards the use of literature in language classes?

$>\quad$ What are the intermediate EFL learners' perceptions towards the use of literature in language classes?

\section{Method}

The design of this study was pre-test post-test control group design. In this study, only quantitative method was used in order to collect the required data. To this end, close-ended questionnaires were used that provided the quantitative data. The integrated approach to teaching literature was the independent variable whereas motivation of the participants was considered as dependent variable. Further, gender, English proficiency level, and literary background knowledge of the participants were taken into account as control variables.

\subsection{Participants}

Forty female EFL leaners, with their ages varying from 18 to 25, and a mean age of 20.72, at intermediate level were selected through convenience sampling. They were randomly assigned to an experimental group and a control group (20 students in each group). None of the participants was a student of English language and literature. They were all undergraduate students of different fields of study. The groups experienced identical conditions during the study except for their exposure to the independent variable (treatment). The experimental group was exposed to the suggested integrated approach to teaching literature whereas, for the control group, the lecture-based method was utilized.

\subsection{Instruments and materials}

Oxford Placement Test (OPT) - To make sure that the participants of the study were more or less at the same level of general English proficiency, OPT was administered to both groups prior to the treatment. The test consisted of 60 items. The participants took three parts that included items related to structure, vocabulary, and reading comprehension with a maximum possible score of 60 points. Based on the test, those students who got a score between 35 to 40 were at middle intermediate level. Since OPT is a standard test, it has been considered as both valid and reliable.

Motivation questionnaire - A motivation questionnaire was administered to evaluate the learning experience of the students in the experimental and control groups at pre- and post-treatment stages. To this end, Motivated Strategies for Learning Questionnaire (MSLQ) was used. As stated by Duncan and McKeachie (2005), this questionnaire was developed by McKeachie and Pintrich in 1986 to evaluate students' learning motivation. Several studies revealed that MSLQ is a valid and reliable instrument (Barker \& Olsen, 2002). The MSLQ consists of 81 items and is divided into two broad categories: (1) a motivation section and (2) a learning strategies section. According to the manual of MSLQ, the motivation section consists of 31 items that assess learners' goals and value beliefs for a given course, their beliefs about their skill to succeed in the course, and their anxiety about tests in the course. Therefore, the motivation section of the test was used in order to serve the 
purpose of the study. It was translated into Persian to make it easier for the participants and to avoid any misunderstanding. The questionnaire consists of 31 items using a seven-point Likert scale in which "1" stands for "not at all true of me" and "7" stands for "very true of me". The calculated reliability in a pilot study $(n=15)$ was reported as $(\alpha=.836)$ which is considered to be good.

Attitude questionnaire - A close-ended attitude questionnaire was developed based on the existing literature and was distributed among the members of the control and experimental groups after the treatment in order to probe their attitudes towards the literature generally. It consists of 20 items using a five-point Likert scale in which "5" stands for "strongly agree" and " 1 " stands for "strongly disagree". The reliability of the questionnaire in a pilot study $(n=15)$ was reported as $(\alpha=.904)$ which is considered to be excellent.

Short stories - Ten short stories were chosen in order to be covered in both the experimental and control groups throughout the study. As Hişmanoğlu (2005) suggested, when selecting a literary text we should consider needs, motivation, interests, and cultural background of the learners. The stories should be relevant to the learners' real-life experiences, emotions, and dreams. It would be motivating for students to study the literature that is currently being discussed in their society. The difficulty of vocabulary and syntax of the stories were examined and all the texts were analyzed through the readability formula.

The short stories in order of their presentation were: "Luck" by Mark Twain, "Hills like White Elephants" by Ernest Hemingway, "The Chaser" by John Collier, "The Lottery" by Shirley Jackson, "Clay" by James Joyce, "Young Goodman Brown" by Nathaniel Hawthorne, "The Guest" by Albert Camus, "A Hunger Artist" by Franz Kafka, "That Evening Sun" by William Faulkner, and "The Chrysanthemums" by John Steinbeck.

\subsection{Procedures}

First of all, the idea of the study was introduced and briefly explained to intermediate classes at the institute under study. Those students who were interested in taking part in the study were selected through convenience sampling and then they were randomly assigned to the experimental and control groups. The selected short stories to be read by the participants were supposed to be covered as a side-program along with their routine EFL classes at the institute. The study was conducted over a period of two months, including 12 sessions (12 hours) of instruction and discussion. In the next step, the Oxford Placement Test was distributed among the participants in order to examine their general English language proficiency and a motivation questionnaire (piloted with the reliability being $\alpha=.836$ ) was handed out as a pre-test.

In both the experimental and control groups, the short stories were given to the students not all together, but one at the time throughout the term. They were asked to read a short story for the following session. At the end of each session, the story to be read for the upcoming class was distributed among the students. The introductory sessions in each group were devoted to the explanation of key literary terms and short story elements including plot, characters, theme, point of view, symbols, and irony and a handout including a summary of the short story elements and key literary terms were given to the learners. After the completion of discussions on all short stories, in both groups the motivation and attitude questionnaires were administrated in order to compare any probable differences between the experimental and control groups.

Procedures in the control group - In this group, the conventional method of teaching literature, lecture-based method, was pursued. The focus of the method was on the writer's intention of writing the story. Therefore, all the necessary information was given without focusing on linguistic or stylistic considerations. The instruction was teacher-centered in which the instructor directed the learners to reach one supposedly 'correct' interpretation of the story. The debate started with the researcher asking about the summery of the story. In order to support and validate the fact that there was only one possible interpretation of the text, the instructor drew learners' attention to particular sections of the story and emphasized the author's intended message of the story by elaborating on the matters being discussed. Thus, the learners were mostly recipients of information and teacher's instruction. Following the story grammar model, they were required to recognize the literary terms and 
The effect of an integrated approach to teaching literature on EFL learners' motivation and attitude

elements of each story, including plot, characters, themes and other literary aspects of the story, and make notes of the following guiding questions later to be discussed in the class about each story (adapted from Cooper, 1986):

Setting: Where/when did the story happen?

Characters: Who were the people in the story?

Theme: What lessons could we learn from the story?

Besides, cultural elements were ignored in this class and they were not elaborated and discussed during the instruction.

Procedures in the experimental group - In this group, an integrated approach to teaching literature (Carter \& Long, 1991; Savvidou, 2004; Divsar \& Tahriri, 2009) was followed which consisted of three phases: linguistic, cultural, and communicative phases. In the linguistic phase, the students took the story home to read with a recommended vocabulary list that included unfamiliar words containing cultural meaning. Besides reading the stories at home, they were encouraged to read aloud the important parts of the story in the class and interpret different parts of it. In the cultural phase, first the instructor provided the necessary information through lecture or by illustrating in the context. Based on teacher's explanations, students discussed different cultural issues and compared the two cultures (English and Persian cultures). Finally, in the communicative phase, students discussed different parts of the stories in pairs and groups and shared their own feelings, ideas, and interpretations of the text with the whole class. In other words, students expressed their opinions about the main characters of the story, whether they liked them or not and if they knew anyone with familiar personality traits in their real lives.

\subsection{Data Analysis}

Mann-Whitney $U$ test was run to answer the first and second research questions since the dependent variable was of ordinal type. In addition, in order to provide an answer for the third research question, descriptive statistics including mean and standard deviation were computed for items of the questionnaire.

\section{Results and discussion}

The non-parametric Mann-Whitney U Test was run to determine if the control and experimental groups differed in terms of their motivation prior to the experiment.

\section{Table 1}

Ranks of the Groups for the Pre-test of Motivation

\begin{tabular}{lllll}
\hline & Groups & N & Mean Rank & Sum of Ranks \\
\hline Total motivation (pre-test) & Control & 20 & 19.68 & 393.50 \\
& Experimental & 20 & 21.33 & 426.50 \\
& Total & 40 & & \\
\hline
\end{tabular}

Table 2

Mann-Whitney U Test for Control and Experimental Groups (pre-test)

\begin{tabular}{lc}
\hline \multicolumn{2}{c}{ Test Statistics ${ }^{\text {a }}$} \\
\hline & Motivation (pre-test) \\
Mann-Whitney U & 183.500 \\
$Z$ & -.447 \\
Asymp. Sig. (2-tailed) & .655 \\
Exact Sig. [2*(1-tailed Sig.)] & $.659^{\mathrm{b}}$ \\
\hline Note. a. Grouping Variable: groups & \\
b. Not corrected for ties. &
\end{tabular}


The $\mathrm{Z}$ value and the significance level, which was given as Asymp. Sig. (2-tailed) were presented in the output. In Table 2 , the $\mathrm{Z}$ value was $(-.447)$ with a significance level of $(p=.655)$. The probability value $(p)$ was greater than (.05), so the result was not found to be significant. This meant that the control and experimental groups were nearly the same in terms of their foreign language motivation at the beginning of the study.

At the end of the study, the non-parametric Mann-Whitney U Test was used to test for the possible differences between the two independent groups on their extent of motivation. In other words, it was run to determine if the control and experimental groups differed in terms of their motivation after receiving the treatment. The ranks for the two groups were compared to see if they differed significantly.

Table 3

Ranks of the Groups for the Post-test of Motivation

\begin{tabular}{lllll}
\hline & Groups & N & Mean Rank & Sum of Ranks \\
\hline Motivation (post-test) & Control & 20 & 19.9 & 398.00 \\
& Experimental & 20 & 21.1 & 422.00 \\
& Total & 40 & & \\
\hline
\end{tabular}

As it was displayed in Table 3, the mean rank of the control group (mean rank control group = 19.9) was somewhat less than that of the experimental group (mean rank experimental group $=21.1$ ).

\section{Table 4}

Mann-Whitney U Test for Control and Experimental Groups (post-test)

\begin{tabular}{lc}
\hline \multicolumn{2}{c}{ Test Statistics $^{\text {a }}$} \\
\hline \multicolumn{2}{c}{ Motivation (post-test) $^{2}$} \\
Mann-Whitney U & 188.000 \\
Z & -.325 \\
Asymp. Sig. (2-tailed) & .745 \\
Exact Sig. [2*(1-tailed Sig.)] & $.758^{\mathrm{b}}$ \\
\hline Note. a. Grouping Variable: groups &
\end{tabular}

b. Not corrected for ties.

In Table 4 , the $\mathrm{Z}$ value was $(-.325)$ with a significance level of $(p=.745)$. The probability value $(p)$ was higher than (.05), so the result was not significant. There was no statistically meaningful difference in the extent of motivation between the control and experimental groups after the treatment. The median values for each group is also presented in Table 5.

\section{Table 5}

Median for the Control and Experimental Groups (Motivation)

\begin{tabular}{llcccccc}
\hline Groups & \multicolumn{3}{c}{ Motivation (pre-test) } & \multicolumn{3}{c}{ Motivation (post-test) } \\
& \multicolumn{2}{c}{$\mathrm{N}$} & Median & \multicolumn{2}{c}{$\mathrm{N}$} & Median \\
\cline { 2 - 3 } & Valid & Missing nnnnnnnn & & & Valid & Missing & \\
\hline Control & 20 & 0 & 4.2742 & 20 & 0 & 4.7097 \\
Experimental & 20 & 0 & 4.3065 & 20 & 0 & 4.6452 \\
\hline
\end{tabular}

As depicted in Table 5, the median value for the motivation of the control group improved from (4.27) in pre-test to (4.70) in post-test. With respect to the experimental group, the median value improved from (4.30) in pre-test to (4.64) in post-test.

Regarding the learners' attitudes towards literature, the non-parametric Mann-Whitney U Test was used to test for the possible differences between the two groups in terms of their perceptions towards the use of literature in language classes at the end of the study. 
The effect of an integrated approach to teaching literature on EFL learners' motivation and attitude

Table 6

Ranks of the Groups for the Post-test of Attitude Questionnaire

\begin{tabular}{lllll}
\hline & Groups & N & Mean Rank & Sum of Ranks \\
\hline Attitude (post-test) & Control & 20 & 16.50 & 330.00 \\
& Experimental & 20 & 24.50 & 490.00 \\
& Total & 40 & & \\
\hline
\end{tabular}

As it was revealed in Table 6, the mean rank of the control group (mean rank control group $=16.50$ ) was less than that of the experimental group (mean rank experimental group $=24.5$ ). Then, the Mann-Whitney U test was run to the ranks for the two groups to see if they differed significantly. The results are displayed in the following table:

Table 7

Mann-Whitney U Test for Control and Experimental Groups (post-test)

\begin{tabular}{lc}
\hline \multicolumn{2}{c}{ Test Statistics $^{\text {a }}$} \\
\hline & Attitude (post-test) \\
Mann-Whitney U & 120.00 \\
Z & -2.168 \\
Asymp. Sig. (2-tailed) & .030 \\
Exact Sig. [2*(1-tailed Sig.)] & $.030^{\mathrm{b}}$ \\
\hline
\end{tabular}

Note a Grouping Variable: groups

b. Not corrected for ties.

In Table 7 , the $\mathrm{Z}$ value was $(-2.168)$ with a significance level of $(p=.030)$. The probability value $(p)$ was less than (.05), so the result was significant. There was a statistically significant difference between the control and experimental groups with respect to their attitudes towards the use of literature in language classes.

In this study, $z=-2.168$ and $n=40$; therefore, the $(r)$ value was (.343). This is considered a medium effect size using Cohen's (1988) criteria of $.1=$ small effect, $.3=$ medium effect, $.5=$ large effect. Therefore, the Mann-Whitney $\mathrm{U}$ test revealed a significant difference in the attitudes of experimental $(M d=3.90, n=20)$ and control $(M d=3.58, n=20)$, Mann-Whitney $\mathrm{U}=120.00, z=-2.168, p=.030, r=.343$.

In order to provide answer for the third research question, descriptive statistics including mean and standard deviation were computed for every item of the questionnaire of both control and experimental groups. The results are presented in the following table:

\section{Table 8}

Item Statistics for the Items of the Attitude Questionnaire

\begin{tabular}{|c|c|c|c|c|}
\hline & $\mathrm{M}$ & SD & $\bar{M}$ & SD \\
\hline & \multicolumn{2}{|c|}{ Cont. } & \multicolumn{2}{|c|}{ Exp. } \\
\hline I like to read English literary works. & 3.95 & .68 & 4.00 & .45 \\
\hline I like to be introduced to more English literary works. & 3.95 & .60 & 4.05 & 68 \\
\hline Studying English literature enhances my learning of English. & 3.40 & 68 & 3.60 & .59 \\
\hline $\begin{array}{l}\text { Studying English literature makes me be more aware of how language forms } \\
\text { and structures can be used to communicate more effectively. }\end{array}$ & 3.00 & .64 & 3.30 & .73 \\
\hline Studying English literature helps me to understand myself and others better. & 3.70 & .57 & 4.20 & 69 \\
\hline $\begin{array}{l}\text { Studying English literature helps me to learn and understand other cultures } \\
\text { and human values better. }\end{array}$ & 3.85 & 67 & 4.65 & .48 \\
\hline Learning English through literature is fun. & 4.10 & .55 & 4.50 & .51 \\
\hline I find studying literature in English personally rewarding. & 3.40 & .59 & 3.80 & .52 \\
\hline $\begin{array}{l}\text { I enjoy reading literature in English if I will be expressing my personal } \\
\text { opinion about it. }\end{array}$ & 4.00 & .00 & 3.80 & .69 \\
\hline $\begin{array}{l}\text { I enjoy reading literature in English if I will be looking for underlying } \\
\text { meaning. }\end{array}$ & 4.00 & .64 & 3.80 & .69 \\
\hline
\end{tabular}


Table 8 ... continued

\begin{tabular}{|c|c|c|c|c|}
\hline & M & SD & M & SD \\
\hline & \multicolumn{2}{|c|}{ Cont. } & \multicolumn{2}{|c|}{ Exp. } \\
\hline I read any types of literary texts in English for pleasure. & 3.45 & 1.1 & 3.40 & .94 \\
\hline I enjoy reading literature about people and experiences similar to my own. & 4.00 & .79 & 4.05 & .68 \\
\hline I enjoy reading literature about people and experiences unlike my own. & 4.25 & .78 & 4.05 & .68 \\
\hline Literature is motivating. & 4.15 & .48 & 4.50 & .51 \\
\hline Literature is boring and a waste of time. & 1.90 & .78 & 1.80 & .76 \\
\hline $\begin{array}{l}\text { Literature is not important to me because it contributes nothing to my future } \\
\text { professional career. }\end{array}$ & 2.45 & 1.05 & 2.75 & .78 \\
\hline $\begin{array}{l}\text { Literature helps me in the process of self-discovery and personal } \\
\text { development. }\end{array}$ & 3.20 & .52 & 3.75 & .44 \\
\hline $\begin{array}{l}\text { Literature gives me a broad sense of ideas for thinking about individual and } \\
\text { social behavior. }\end{array}$ & 3.55 & .60 & 4.20 & .61 \\
\hline I favored the teaching method that was employed in this class. & 3.95 & .51 & 4.40 & .50 \\
\hline I am going to read stories more and more after the study. & 3.50 & .76 & 3.90 & .64 \\
\hline
\end{tabular}

The participants of the control group expressed their highest positive attitude towards several items $(13,14$, $7,9,10$, and 12), respectively. Item (13) received the highest mean rank. This item revealed the respondents' attitudes with respect to "reading literature about people and experiences unlike their own" $(M=4.25)$. Additionally, item (14) got the second highest rank. This item evaluated the respondents' attitudes with respect to "the motivating effect of literature" $(M=4.15)$. In item (7), the respondents' reflection of their high positive perception emphasized "the fun aspect of learning English through literature" $(M=4.10)$. Furthermore, the respondents' high ranking for items $(9,10$, and 12) disclosed, "they enjoyed reading literature in English if they would be expressing their personal opinion about it." $(M=4.00)$, "they enjoyed reading literature in English if they would be looking for underlying meaning." $(M=4.00)$, and "they enjoyed reading literature about people and experiences similar to their own" $(M=4.00)$. In contrast, the respondents' ranking for item (15) that got the lowest mean rank revealed that the majority of them held negative attitude with this item that stated, "Literature was boring and a waste of time" $(M=1.90)$.

For the experimental group, items $(6,7,14,19,5,18,2,12,13$, and 1) had the highest mean rank, respectively. These items examined the participants' attitudes in relation to "the role of studying English literature to learn and understand other cultures and human values better" $(M=4.65)$, "the fun aspect of learning English through literature" $(M=4.50)$, "the motivating effect of literature" $(M=4.50)$, "their appreciation of the teaching method that was employed in the class" $(M=4.40)$, "the effective role of studying English literature to understand themselves and others better" $(M=4.20)$, "the effective role of literature in giving them a broad sense of ideas for thinking about individual and social behavior" $(M=4.20)$, "their inclination to be introduced to more English literary works" $(M=4.05)$, "their appreciation of reading literature about people and experiences similar to their own" $(M=4.05)$, "their appreciation of reading literature about people and experiences unlike their own" $(M=4.05)$, and "their inclination to read English literary works" $(M=4.00)$. On the contrary, the lowest mean rank was reflected for item (15) that examined the respondents' perceptions towards "the possible boring aspect of literature and not putting time to good use" $(M=1.80)$.

Concerning the homogeneity of the responses provided by the control group, the highest degree of diversity $(S D=1.05)$ among the responses was observed for items (16) that scrutinized the respondents' viewpoints with respect to "the contribution of literature to their future professional career". In contrast, the perfect degree of uniformity among the responses $(S D=00)$ was reported for item (9) that inspected their attitudes towards "their appreciation of reading literature in English if they would be expressing their personal opinion about it". For the experimental group, the responses were widely varied in item (11) with standard deviation of about (.94) that assessed their perceptions with respect to "reading any types of literary texts in English for pleasure". However, for item (17) the highest degree of consistency among the responses was reported $(S D=.44)$ that appraise their ranking of "the effective role of Literature in the process of self-discovery and personal development". 
The effect of an integrated approach to teaching literature on EFL learners' motivation and attitude

It was already discussed that what motivated this research was the observed problems in EFL literature classes in Iran as well as learners' lack of motivation. It was assumed that teaching literature could be more motivating if an integrated approach were adopted in an EFL class. It was hypothesized that lack of motivation could be filled with the implementation of literature in EFL classes following a systematic approach that allows room for increasing learners' motivation. Moreover, it was already pointed out that there has been an increasing awareness of the significance of integrating literature in EFL curriculum. A syllabus that is based, or that draws heavily on authentic stories, provides a motivating medium for language learning. Literature is said to be fundamentally a study of language and literature is language in use and cannot be separated from language (Widdowson, 1985).

The results revealed that though the students in both groups were motivated and interested enough in reading short stories at the beginning of the study, their motivation for further studies of English literary works and English short stories increased. Both groups showed an increase in the degree of motivation, of which the magnitude for the experimental group was higher; however, the difference between the groups was not statistically significant. Therefore, the general procedures in both groups could not only maintain, but also elevate the learners' motivation. Concerning the less stressed atmosphere that integrated approach created, due to the point that the learners were not under the pressure of finding one correct interpretation of the text, this method was more successful in promoting the participants' motivation. The important achievement of this study was that the learners of both groups were highly interested in the method applied in their classes, of which the magnitude for the experimental group was higher. The systematic implantation of each method that followed a specific framework yielded this result. The results are in line with Vural's (2013) study in terms of motivation. Considering the innovative, challenging, and new horizons that the integrated approach proposed, the students favored this method more than the one in the control group. It can be concluded that literature can be used as a positive stimulation to motivate students.

It has been identified that the attitudes of learners' studying literature through the integrated approach was more positive than those of the control group that is in line with the results of the previous studies (Davis, Gorrell, Kline, \& Hsieh, 1992). Further, they are consistent with the previous studies (Yilmaz, 2012; Akyel \& Yalçin, 1990) in which literary texts and language were combined (T-seng, 2010). In addition, analysis of the descriptive statistics showed that the majority of participants in the experimental group held very positive attitudes towards the applied integrated approach and literature generally.

\section{Conclusions}

Regarding the students' attitudes and perceptions of literature instruction, the results shed light on what and how to teach foreign language literature in EFL classes. The results can have both theoretical and practical implications. First and foremost, like numerous studies (Carter \& Long, 1991; Duff \& Maley, 1991; Lazar, 1993), which supported placing literature in language pedagogies, literature proved to be helpful in this study as well. Implementing literature helps EFL teachers provide the learners with authentic, interesting, effective, and challenging materials that promote the learners' motivation (Van, 2009). However, selecting the right stories is a meticulous task which requires taking a number of factors into consideration. The literary texts should be appropriate materials for both the proficiency level of the students and contain discussable and challenging themes and contents. Another point to be referred to is that the genre of short stories is assumed to be generally easier for the students to go through in comparison with poetry or novels.

In conclusion, if teachers are interested in using literature in their EFL classes, the literary texts they select have to be appropriate and in accordance with their students' levels of proficiency, interests, and needs. As a result, the students will be highly motivated to complete the varying task given and participate in class discussions. This study proposed a systematic approach which enhanced learners' motivation for further studies of English literature. Considering the integrated approach, it was found that this approach to teaching literature dominates the conventional lecture-based method regarding the learners' motivation and attitudes towards the 
Amirani, D., Tahriri, A., \& Barekat, B.

use of literature in EFL classes. This view can be generalized to teaching in EFL classes in which the goal of instruction is increasing learners' motivation and positive attitudes towards the use of literature.

In short, EFL instructors should follow a systematic approach in the implementation of short stories. They need to help the learners to foster both the knowledge of the language and their motivation. In this way, the students will gradually become more motivated for reading English literature. The primary purpose is to help teachers and students move from traditional approaches to more innovative ways in teaching/learning literature as increasing their motivation and positive attitudes towards the literature in language classes, and in the second place to make the policy makers, syllabus designers, and material producers aware of the significance of incorporating literature in EFL classes.

\section{References}

Akyel, A., \& Yalçin, E. (1990). Literature in the EFL class: A study of goal-achievement incongruence. ELT Journal, 44(3), 174-180. http://dx.doi.org/10.1093/elt/44.3.174

Barker, J. R., \& Olsen, J. P. (2002). Medical students' learning strategies: Evaluation of first-year changes. Retrieved from http://www.msstate.edu/org/MAS/ejour2.html

Bassnett, S., \& Grundy, P. (1993). Language through literature. London: Longman.

Berg, E. S. (2001). An assessment of community college students' learning styles, choice of instructional delivery method, withdrawal rates, and performance in writing intensive courses. Dissertation Abstracts International, 62(10), 32-46.

Brown, H. D. (1994). Teaching by principles: An interactive approach to language pedagogy. NJ: Prentice Hall Regents.

Brumfit, C. J., \& Carter, R. A. (1986). Literature and language teaching. Oxford: Oxford University Press.

Carter, R., \& Long, M. N. (1991). Teaching literature. Harlow, Essex: Longman.

Cohen, J. (1988). Statistical power analysis for the behavioral sciences $\left(2^{\text {nd }}\right.$ ed.). Hillsdale, NJ: Lawrence Earlbaum Associates.

Cooper, J. P. (1986). Improving reading comprehension. Boston: Houghton Mifflin.

Davis, J. N., Gorell, L. C., Kline, R. R., \& Hsieh, G. (1992). Readers and foreign languages: A survey of undergraduate attitudes toward the study of literature. The Modern Language Journal, 76(3), 320-332. http://dx.doi.org/10.1111/j.1540-4781.1992.tb07002.x

Deci, E. L., \& Ryan, R. M. (1995). Human autonomy: The basis for true self-esteem. In M. Kernis (Ed.), Efficacy, agency, and self-esteem (pp. 31-49). New York: Plenum Publishing Co. http://dx.doi.org/10.1007/978-1-4899-1280-0_3

Divsar, H., \& Tahriri, A. (2009). Investigating the effectiveness of an integrated approach to teaching literature in an EFL context. Journal of Pan-Pacific Association of Applied Linguistics (PALL), 2(13), 105-116.

Dörnyei, Z. (1994). Motivation and motivating in the foreign language classroom. The Modern Language Journal, 78(3), 273-284. http://dx.doi.org/10.1111/j.1540-4781.1994.tb02042.x

Dörnyei, Z., \& Ottó, I. (1998). Motivation in action: A process model of L2 motivation. Working Papers in Applied Linguistics, 4, 43-69.

Duff, A., \& Maley, A. (1991). Literature. Oxford: Oxford University Press.

Duncan, T. G., \& McKeachie, W. J. (2005). The making of the Motivated Strategies for Learning Questionnaire. Educational Psychologist, 40(2), 117-128. http://dx.doi.org/10.1207/s15326985ep4002_6

Gardner, R. C. (1985). Social psychology in second language learning: The role of attitudes and motivation. London: Edward Arnold.

Ghosn, I. (2002). Four good reasons to use literature in primary school ELT. ELT Journal, 56(2), 172-179. http://dx.doi.org/10.1093/elt/56.2.172

Gower, R., \& Pearson, M. (1986). Reading literature. London: Longman.

Guariento, W., \& Morley, J. (2001). Text and task authenticity in the EFL classroom. ELT Journal, 55(4), 347-353. http://dx.doi.org/10.1093/elt/55.4.347 
The effect of an integrated approach to teaching literature on EFL learners' motivation and attitude

Hill, J. (1986). Using literature in language teaching. London: Macmillan.

Hişmanoğlu, M. (2005). Teaching English through literature. Journal of Language and Linguistic Studies, 1(1), 53-66.

Khatib, M., Rezaei, S., \& Derakhshan, A. (2011). Literature in EFL/ESL classroom. English Language Teaching, 4(1), 201-208. http://dx.doi.org/10.5539/elt.v4n1p201

Khodashenas, M. R., Amouzegar, E., Farahani, S. K., Hasheminasab, S. G. H., \& Kazemian, V. (2013). Review article: Role of motivation in language learning. International Research Journal of Applied and Basic Sciences, 6(6), 766-773.

Lazar, G. (1993). Literature and language teaching: A guide for teachers and trainers. Cambridge: Cambridge University Press. http://dx.doi.org/10.1017/CBO9780511733048

Lightbown, P., \& Spada, N. (2000). Do they know what they 're doing? L2 learners' awareness of L1 influence. Language Awareness, 9(4), 198-217. http://dx.doi.org/10.1080/09658410008667146

Lima, C. (2005). Is the rest silence...?. International Association of Teachers of English as a Foreign Language Voices, 186. Retrieved from http://associates.iatefl.org/pages/materials/voicespdf/ltskills11.pdf

Maley, A. (1989). Down from the pedestal: Literature as resource. In C. J. Brumfit \& R. A. Carter (Eds.), Literature and the learner: Methodological approaches (pp. 10-23). London: McMillan.

Maley, A., \& Duff, A. (1989). The inward ear: Poetry in the language classroom. Cambridge: Cambridge University Press.

Mao, Z. (2011). A study on L2 motivation and applications in reading class in senior high school. Theory and Practice in Language Studies, 1(12), 1731-1739. http://dx.doi.org/10.4304/tpls.1.12.1731-1739

McKay, S. (1986). Literature in the ESL Classroom. In C. J. Brumfit \& R. A. Carter (Eds.), Literature and language teaching (pp. 191-198). Oxford: Oxford University Press.

McRae, J. (1991). Literature with a small ' $l$ '. London: Macmillan.

Meristo, M. (2009). Motivational aspects in teaching English culture and literature: A narrative analysis. Pays Riverains de la Baltique, 6, 181-194.

Nuttall, C. (1996). Teaching reading skills in a foreign language. Oxford: Heinemann.

Oxford, R., \& Shearin, J. (1994). Language learning motivation: Expanding the theoretical framework. Modern Language Journal, 78, 12-28. http://dx.doi.org/10.1111/j.1540-4781.1994.tb02011.x

Povey, J. F. (1967). Literature in TESOL programs: The language and the culture. TESOL Quarterly, 1, 40-46. http://dx.doi.org/10.2307/3585752

Pugh, S. (1989). Literature, culture, and ESL: A natural convergence. Journal of Reading, 32, 320-329.

Rahimi, S. (2014). The use of literature in EFL classes. Journal of Academic and Applied Studies, 4(6), 1-12.

Savvidou, C. (2004). An integrated approach to the teaching of literature in the EFL classroom. The Internet TESL Journal, 10(12). Retrieved from http://iteslj.org/Techniques/Savvidou- Literature.html

Scarcella, R., \& Oxford, R. (1992). The tapestry of language learning: The individual in the communicative classroom. Boston: Heinle \& Heinle Publishers.

Shih, C., \& Gamon, J. (2001). Web based learning: Relationship among student motivation, attitude, learning styles, and achievement. Journal of Agricultural Education, 42(2), 12-20. http://dx.doi.org/10.5032/jae.2001.04012

Skehan, P. (1991). Individual differences in second language learning. Studies in Second Language Acquisition, 13, 275-298. http://dx.doi.org/10.1017/S0272263100009979

Timucin, M. (2001). Gaining insight into alternative teaching approaches employed in an EFL literature class. Revista de Filología y su Didáctica, 24, 269-293.

T-seng, F. (2010). Introducing literature to an EFL classroom: Teachers' presentations and students' perceptions. Journal of Language Teaching and Research, 1(1), 53-65.

Van, T. T. M. (2009). The relevance of literary analysis to teaching literature in the EFL classroom. English Teaching Forum, 3, 2-9.

Vural, H. (2013). Use of literature to enhance motivation in ELT classes. Mevlan International Journal of Education, 3(4), 15-23. http://dx.doi.org/10.13054/mije.13.44.3.4

Wasanasomsithi, P. (1998). An investigation into teachers' attitudes toward the use of literature in the Thai EFL 
Amirani, D., Tahriri, A., \& Barekat, B.

classroom. Doctoral dissertation, The Indiana University, USA.

Wellek, R., \& Warren, A. (1948). Theory of literature. USA: Harcourt, Brace \& Company.

Widdowson, H. G. (1985). The teaching, learning and study of literature. Cambridge: Cambridge University Press.

Yilmaz, C. (2012). Introducing literature to an EFL classroom: Teacher's instructional methods and students' attitudes toward the study of literature. English Language Teaching, 5(1), 86-99. 